\section{PRESERVING THE AFOS FLAG}

In honor of the $50^{\text {th }}$ anniversary of the Armed Forces Optometric Society's founding earlier this year, the Archives \& Museum of Optometry staff used the milestone as an excuse to do some preservation work on the flag presented to the AOA in 1970 by AFOS's first officers.

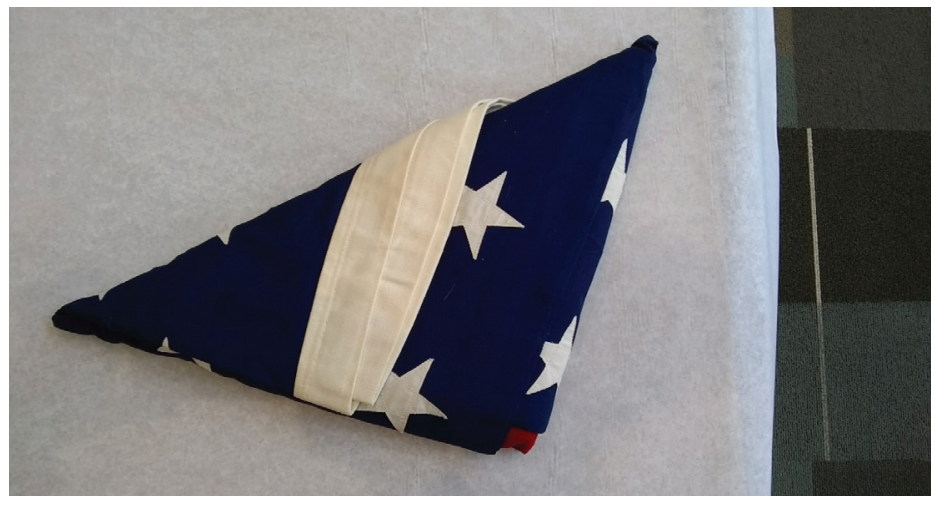

Image courtesy of The Archives and Museum of Optometry.

The $5^{\prime}$ by 8 ' cotton DETTRA brand flag presented to the AOA in 1970 was flown at the Capitol Building in Washington, D.C. It has remained folded, wrapped in butcher paper and hidden in a box for 50 years.

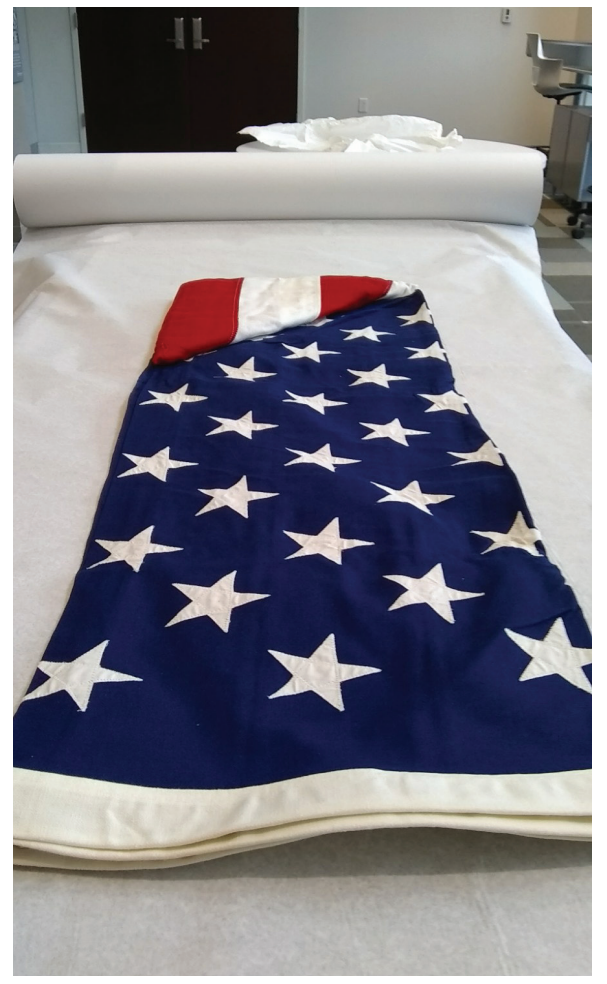

Image courtesy of The Archives and Museum of Optometry.

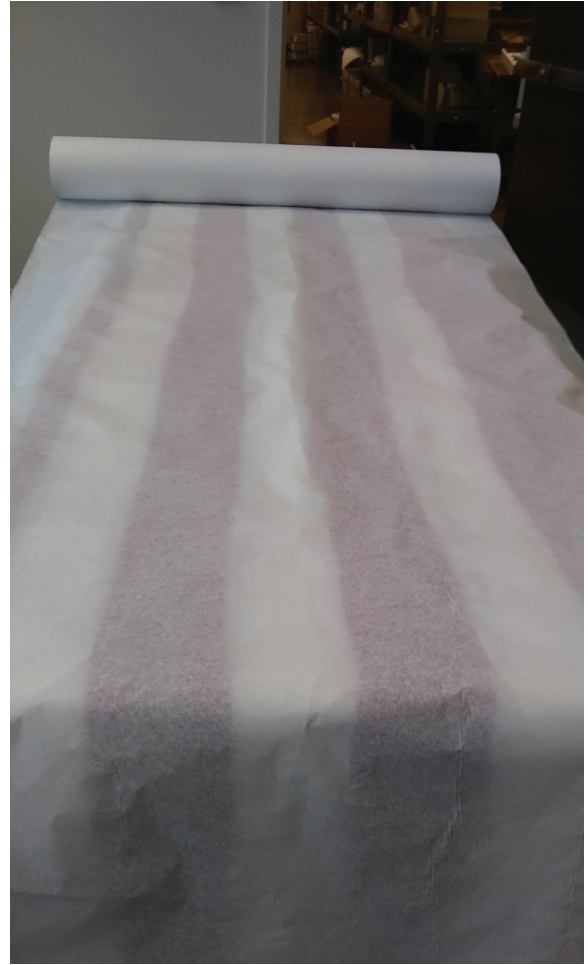

Completely unfurled and inspected, we made sure tissue was placed on top and below (interleaved) to prevent abrasion or bleeding when stored. Because the flag is so large, we compromised and made a fold along a seam to reduce the length of the finished tube.

Image courtesy of The Archives and Museum of Optometry.

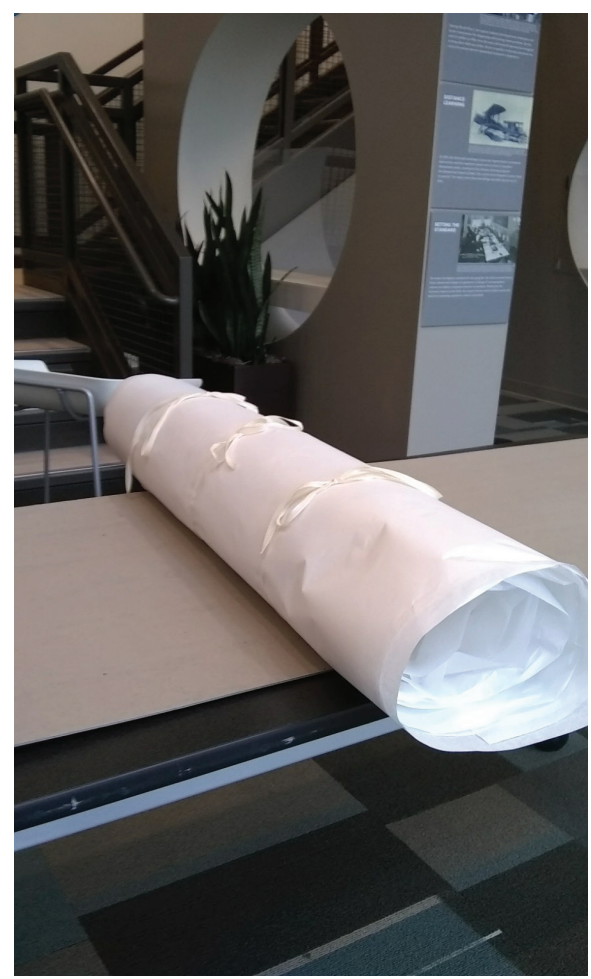

Once the flag was rolled, carefully beginning at the hoist end, we used unbleached cotton twill "tape" (ribbon) to secure the roll. Now, the flag can be stored in archival shelving safely for many years to come!
Image courtesy of The Archives and Museum of Optometry. 


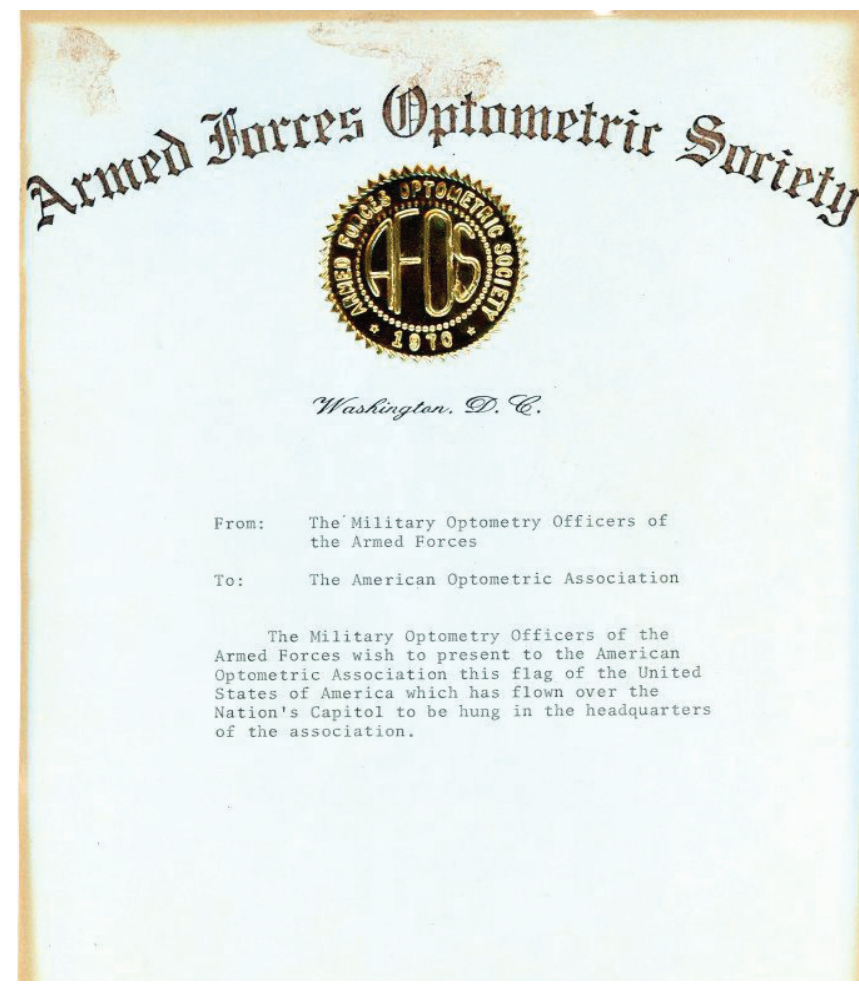

In 1970, the AFOS gift to the AOA was accompanied by framed memorandum commemorating the occasion. Unfortunately, the memo was adhered to the acidic, cardboard matting. The adhesive eventually failed, but not before bleeding through and leaving residue. The acidic backing material also caused discoloration along the edges of the memo. Our preservation measures included removing the memo from the frame, encapsulating in clear polyester and making a digital copy to minimize use.

Image courtesy of The Archives and Museum of Optometry.

\section{OFDR \\ OPTOMETRY'S FUND \\ FOR DISASTER RELIEF}

\section{We are here when you need to rebuild.}

Tornadoes. Floods. Civil unrest.

Hurricanes. Fires. Earthquakes.

We stand ready to help in times of need so doctors can return to providing vision care for their communities.

To apply for aid or to donate to the cause, please visit aoafoundation.org/OFDR.

$\therefore \because \because \because$

OPTOMETRY CARES

$\because \because \quad$ The AOA Foundation 